\title{
ANALISIS PERBANDINGAN METODE QUEUE PADA MIKROTIK
}

\author{
Joko Dwi Santoso \\ Teknik Komputer / Ilmu Komputer, Universitas AMIKOM Yogyakarta \\ Jl. Ring Road Utara, Condong Catur, Sleman, Yogyakarta, 55283 \\ $(0274-884201-207 ; 0274-884208)$ \\ joko@amikom.ac.id
}

\begin{abstract}
Abstrak: Kemajuan teknologi sekarang sangat berkembang, semua informasi dan mudah tersedia dengan mudah diperoleh. Namun, tidak mudah menggunakan teknologi secara optimal, tidak sedikit pengguna jaringan internet skala besar atau kecil tidak mengetahui pengelolaan bandwidth yang mereka gunakan setiap hari. Saat ini ada banyak penyedia layanan internet atau penyedia, baik nasional maupun internasional. Membuat perangkat keras begitu banyak perangkat keras yang kami temui di mana-mana. Tentu saja industri dalam teknologi informasi sangat membantu kita untuk melakukan banyak hal, salah satunya adalah mengoptimalkan kinerja internet atau manajemen bandwidth dari jaringan yang kita miliki Perlunya manajemen yang baik untuk mendapatkan hasil yang memuaskan. Salah satu bandwidth manajemen yang dapat kita gunakan adalah Simple Quеue dan Queue Tree pada Microtic Router Board. Distribusi bandwidth yang baik rata-rata akan membuat akses lebih stabil dan lebih cepat.

Kata Kunci: Manajemen Bandwidth, Akses Internet Simple Quеие, Tree Queuе
\end{abstract}

\begin{abstract}
Advances in technology are now highly developed, all information and easily available easily obtained. However, it is not easy to use technology optimally, not a few large or small scale internet network users do not know the bandwidth management they use every day. At present there are many internet service providers or providers, both national and international. Making hardware is so much hardware that we have encountered everywhere. Of course the industry in information technology really helps us to do many things, one of which is to optimize internet performance or bandwidth management of our network. The need for good management to get satisfying results. One of the bandwidth management that we can use is Simple Queue and Queue Tree on the Microtic Router Board. A good bandwidth distribution on average will make access more stable and faster.
\end{abstract}

Keywords - Bandwidth Management, Internet Access, Simple Queue, Tree Queue

\section{PENDAHULUAN}

Komunikasi menggunakan teknologi internet hampir menjadi kebutuhan primer pada setiap orang saat ini. Hampir setiap orang didunia ini memelerlukan jaringan internet untuk kebutuhan sehari-hari. Jaringan Wireless Fidelity atau yang biasa disebut wifi sudah sangat tidak asing di telinga kita, karena pada saat ini sangat mudah kita temukan di berbagai tempat seperti di kantor, diinstansi Pendidikan ataupun pada sektor bisnis terdapat jaringan Wireless.

Wireless merupakan jaringan komputer yang dapat digunakan untuk menghubungkan antar perangkat jaringan tanpa menggunakan perantara media kabel, Yaitu dengan menggunakan gelombang elektromagnetik sebagai pengganti media kabel. Jaringan wireless memiliki nilai konsumsi transfer data bit per secon antara server dan client yang di pengaruhi oleh jumlah pemakai Wireless itu sendiri, untuk bisa mendapatkan nilai konsumsi bit per second yang baik dapat menggunakan metode manajemen bandwidth Simple Quеие dan Quеие Tree. Dengan fitur pada router mikrotik berupa metode Queue Simpel dan Queue Tree dapat 
Jurnal Pseudocode, Volume VII Nomor 1, Februari 2020, ISSN 2355-5920, e-ISSN 2655-1845 www.ejournal.unib.ac.id/index.php/pseudocode

mengetahui performa jaringan untuk meningkatkan kualitas pelayanan pada bandwidth yang stabil, sehingga kebutuhan bandwith dapat tersebar dengan merata dan terbagi secara merata.

\section{TINJAUAN PUSTAKA}

\section{A. Pengertian Jaringan}

Menurut Ariyus dan Andri (2008), sebuah jaringan komputer sekurang-kurangnya terdiri dari dua unit komputer atau lebih, dapat berjumlah puluhan komputer, ribuan atau bahkan jutaan node yang saling terhubung satu sama lain.

\section{B. Pengertian Mikrotik}

Mikrotik merupakan perusahaan produsen perangkat jaringan komputer. Saat ini produk mikrotik sudah banyak digunakan oleh pelaku bisnis di bidang komputer, seperti warnet, ISP (Internet Service Provider), perusahaan kecil hingga besar, bisnis rumahan dan lain sebagainya. Adapun beberapa fitur yang dapat digunakan di Mikrotik adalah :

1. NAT

\section{Network Address Translation}

merupakan salah satu fasilitas router Mikrotik untuk meneruskan paket dari IP public ke IP tujuan (lokal). Pada dasarnya golongan IP local tersebut hanya dapat digunakan pada satu jaringan LAN. Maka dari itu, fitur NAT yang ada pada Mikrotik berfungsi untuk menutupi alamat IP local dengan sebuah alamat IP public, dengan begitu alamat IP local pun dapat mengakses internet karena memiliki alamat IP publik yang menutupinya.

Terdapat dua jenis NAT, yaitu Source NAT (srcnat) serta Destination NAT (dsnat). Jika tanpa NAT, maka komputer client tidak akan bisa mengakses gateway internet termasuk juga mengakses internet atau DNS server. Maka dari itu, Mikrotik harus diberikan konfigurasi NAT terlebih dahulu agar semua client yang terhubung mampu mengakses internet.

\section{DNS}

DNS (Domain Name System) digunakan untuk menerjemah alamat IP ke domain address dan sebaliknya. Misalnya, mengakses situs www.facebook.com pada web browser, maka DNS akan menerjemahkan kealamat IP public situs Facebook yaitu 31.13.78.35 dan menampilkan halaman Facebook di layar monitor.

Biasanya ISP memberikan duah buah DNS, yaitu primary DNS sebagai DNS utama dan secondary DNS untuk DNS cadangan jika DNS utama mengalami error, secondary DNS juga membantu kerja DNS utama dalam menerjemahkan situs web kealamat IP publik.

3. DHCP

DHCP merupakan singkatan dari Dynamic Host Configuration Protocol. DHCP merupakan suatu protokol dalam suatu jaringan komputer yang memungkinkan pembagian/ distribusi alamat IP kekomputer client secara dinamik/ otomatis tanpa harus mengatur pada komputer client satu persatu. Mikrotik dapat diatur menjadi DHCP Server sekaligus menjadi gateway, dimana komputer client harus terhubung ke Mikrotik dan melakukan request terlebih dahulu untuk bisa mendapatkan alamat IP dan selanjutnya dapat terhubung ke internet.

4. Firewall

$$
\text { Firewall merupakan perangkat }
$$

yang berfungsi untuk memeriksa dan menentukan paket data yang dapat keluar 
Jurnal Pseudocode, Volume VII Nomor 1, Februari 2020, ISSN 2355-5920, e-ISSN 2655-1845 www.ejournal.unib.ac.id/index.php/pseudocode

atau masuk dari sebuah jaringan. Dengan kemampuan menentukan apakah paket data bisa masuk dan keluar dari suatu jaringan maka firewall berperan untuk melindungi jaringan dari serangan yang berasal dari internet. Selain ditujukan untuk melindungi jaringan, firewall juga difungsikan untuk melindungi sebuah komputer user atau host (single host, firewall jenis ini disebut host firewall).

5. Mangle

Mangle merupakan salah satu fitur pada firewall Router Mikrotik yang digunakan untuk memberi tanda (mark) pada paket data. Kadang pekerjaan memberi tanda ini disebut marking, tujuan untuk memberikan tanda ini dimaksudkan agar paket tersebut lebih mudah dikenali lagi, yang pada akhirnya mempermudah dalam menerapkan filter, masquerade, routing maupun pada saat akan melakukan manajemen bandwidth. Untuk menerapkan Quality of Service (QoS). Sangat penting untuk melakukan traffic classification terlebih dahulu. Dalam proses traffic classification harus dapat memisahkan berbagai macam traffic yang ada di dalam jaringan. Untuk dapat memisahkan berbagai jenis traffic tersebut maka harus membuat marking packet.

\section{Hotspot}

Hotspot merupakan salah satu fitur dari mikrotik untuk membuat jaringan wifi melalui wireless AP. Berbeda dengan wifi biasa ketika ingin terhubung harus memasukkan password untuk mengakses wifi, sedangkan Hotspot memberikan akses ke setiap client untuk dapat terhubung kejaringan secara langsung tanpa memerlukan password, namun ketika sudah terhubung client akan diarahkan ke halaman login pada web browser. Setiap client dapat login dengan username dan password yang berbeda- beda. Sebenarnya Hotspot tidak hanya diaplikasikan pada jaringan wireless saja, namun juga bisa untuk jaringan kabel. Kelebihan hotspot adalah dapat dikonfigurasikan suatu username dan password sehingga hanya yang terdaftar saja yang dapat menikmati akses dalam jaringan. Selain itu dapat dilakukan manajemen pengguna, seperti: mengatur life time, bandwidth, dan lain sebagainya.

7. User Manager

User Manager atau sering disingkat UserMan merupakan fitur AAA server yang dimiliki oleh router Mikrotik. Sesuai kepanjangannya yaitu AAA (Authentication, Authorizaion, dan Accounting). User Manager memiliki database yang bisa digunakan untuk melakukan autentikasi client yang login ke dalam network Mikrotik serta memberikan kebijakan terhadap user tersebut misalnya limitasi transfer rate dan juga perhitungan serta pembatasan kouta yang dilakukan semua client.

User Manager ini akan memudahkan untuk membuat layanan internet public secara luas, misalnya pembuatan Hotspot di cafe, mall, hotel dan sebagainya, karena dengan menggunakan User Manager ini cukup membuat satu akun user dan akun user tersebut bisa digunakan atau diakses dari router atau AP Hotspot yang sudah dipasang dibeberapa titik.

8. Simple queue

Merupakan metode bandwidth management termudah yang ada di Mikrotik. 
Jurnal Pseudocode, Volume VII Nomor 1, Februari 2020, ISSN 2355-5920, e-ISSN 2655-1845 www.ejournal.unib.ac.id/index.php/pseudocode

Menu dan konfigurasi yang dilakukan untuk menerapkan simple quеие cukup sederhana dan mudah dipahami. Walaupun namanya simple quеие sebenarnya parameter yang ada pada simple queue sangat banyak, bisa disesuaikan dengan kebutuhan yang ingin diterapkan pada jaringan. Parameter dasar dari simple quеие adalah Target dan Max-limit. Target dapat berupa IP address, network address, dan bisa juga interface yang akan diatur bandwidthnya. Max-limit Upload / Download digunakan untuk memberikan batas maksimal bandwidth untuk target.

9. Queuetree

Qиеие Tree merupakan suatu bentuk konfigurasi manajemen bandwidth yang cukup kompleks karena dapat disesuaikan berdasarkan protokol, nomor port atau pengeompokkan berdasarkan alamat IP. Sebelum melakukan limit bandwidth, anda harus menandai aliran paket menggunakan suatu tanda mangle (istilah pada mikrotik) agar paket tersebut dapat dikenal oleh Quеие Tree. Hal ini bertujuan membedakan paket data yang hanya Downlink atau Uplink sehingga limit bandwidth dapat bekerja secara optimal.

10. PCQ

PCQ (Per Connection Queuing)

digunakan untuk mengenali arah arus dan digunakan karena dapat membagi bandwidth secara merata dan bersamaan. PCQ pada Mikrotik digunakan bersama dengan fitur Queue, baik Simple Quеие maupun Quеие Tree.

NDLC (Network Development Life Cycle)

Network Development Life Cycle

(NDLC) merupakan sebuah metode yang bergantung pada proses pembangunan sebelumnya seperti perencanaan strategi bisnis, daur hidup pengembangan aplikasi, dan analisis pendistribusian data.

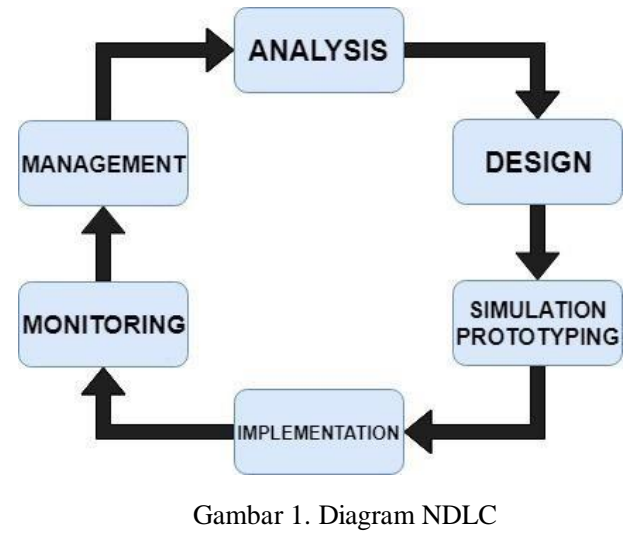

III. METODE PENELITIAN

A. Implementasi

1. Analisis Masalah

Kendala pada faktor sistem bandwith yang menjadikan koneksi internetnya tidak stabil, dimana jika ada yang men-download file dengan sekala besar terutama yang menggunakan download manager dapat langsung membuat bandwidth penggunaan data tidak stabil. Maka dari itu pada penelitian ini akan membandingkan dua metode queue simple dan queue tree untuk mengetahui metode mana yang paling sesuai untuk jaringan skala menengah.

2. Design

Dari semua hasil analisis yang telah dilakukan, tahap desain kali ini berfungsi untuk membuat perencanaan yang lebih efektif. Selain itu pada tahp ini juga memilih perangkat apa saja yang akan digunakan.

a. Kebutuhan Sistem

b. Perangkat Keras

1. Laptop

Berfungsi untuk menganalisis dan pengumpulan data yang diperlukan untuk konfigurasi Mikrotik dan testing konfigurasi. 
Jurnal Pseudocode, Volume VII Nomor 1, Februari 2020, ISSN 2355-5920, e-ISSN 2655-1845 www.ejournal.unib.ac.id/index.php/pseudocode

\begin{tabular}{|c|c|}
\hline $\begin{array}{l}\text { Perangkat ini juga digunakan dalam } \\
\text { penyusunan laporan dan pengolahan data. }\end{array}$ \\
\hline Spesifikasi & Dalam Penelitian \\
\hline Processor & Intel Core i3 \\
\hline RAM & 4 \\
& G \\
\hline VGA & Nvidia Geforce 920MX \\
\hline OS & Windows 10 \\
\hline
\end{tabular}

2. RouterBoard Mikrotik

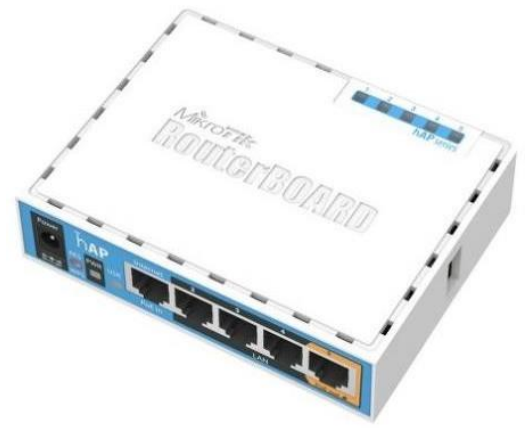

Gambar 2. Routerboard Mikrotik

RouterBoard Mikrotik RB95Iui-2ND digunakan sebagai pusat konfigurasi jaringan hotspot. dengan spesifikasi sebagai berikut:

a. Procecor QCA9531-BL3A-R 650 $\mathrm{MHz}$.

b. Product Code Rb951Uind

c. Architecture MIPS-BE

d. Main Storage/NAND 16MB

e. $\operatorname{Ram} 64 M B$

f. LAN Ports 5

g. Switch Chip 1

h. Integrated Wireless 1

i. Wireless Standarts $802.11 \mathrm{~b} / \mathrm{g} / \mathrm{n}$

j. Wireless Tx Power 22dbm

k. USB 1

1. Power on USB
m. Power Jack 8-30V
n. POE Input
o. POE Output Port 5

\section{Modem ISP (HUAWEI HG8245A)}

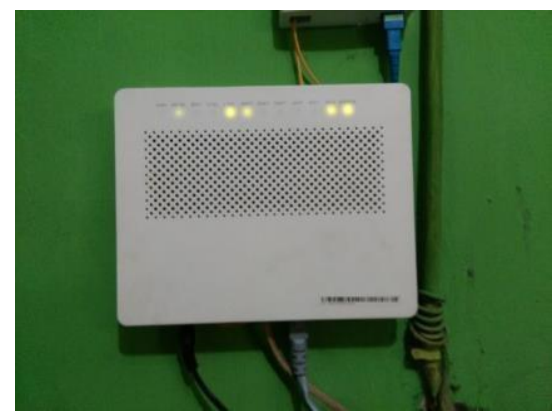

Gambar 3. Modem ISP

Untuk menghubungkan jaringan internet ke jaringan hotspot pada penelitian menggunakan modem standar yang disewakan dari pihak provider, dalam hal ini menggunakan layanan internet fiber indihome dari Telkom.

4. Kabel UTP

Kabel UTP CAT5E (Unshield Twisted Pair) digunakan untuk menghubungkan device network ke device network lain.

c. Perangkat Lunak

1) Router OS

RouterOS yang digunakan yaitu Mikrotik versi 6.41 berlisensi 4 .

2) Winbox

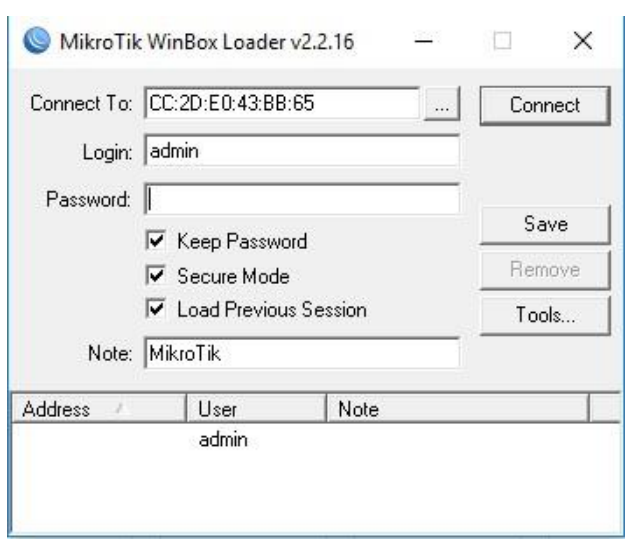

Gambar 4. Tampilan Winbox 
Jurnal Pseudocode, Volume VII Nomor 1, Februari 2020, ISSN 2355-5920, e-ISSN 2655-1845 www.ejournal.unib.ac.id/index.php/pseudocode

Winbox merupakan sebuah softwere atau utility yang digunkan untuk meremot ke sebuah server Mikrotik dalam Mode GUI (Graphical User Interface) untuk dapat melakukan konfigurasi melalui laptop.

3) Speedtest

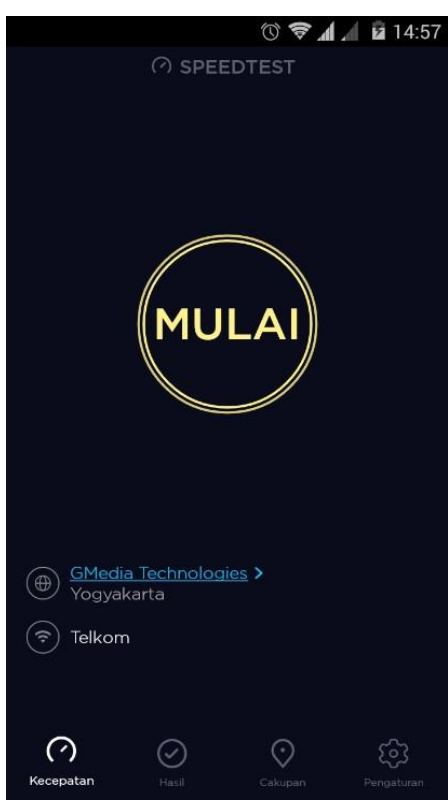

Gambar 5. Speedtest

Merupakan aplikasi web yang menyediakan layanan pengujian kecepatan koneksi bandwidth internet yang dapat diakses melalui www.beta.speedtest.net/id speed test tersedia juga untuk pengguna iOS, Android, Google Chrome, MacOS dan Windows. Situs ini berjalan mulai tahun 2006 sebanyak 20 juta pengguna internet yang menggunakan situs ini untuk pengecekan kecepatan internet setiap bulannya.

\section{B. Topologi Jaringan Baru}

Topologi yang akan digunakan adalah dengan menambahkan perangkat baru yaitu berupa Router Mikrotik RB-951Ui-2ND. Mikrotik berfungsi untuk memanajemen bandwidth. Berikut ini adalah topologi jaringan baru yang digunakan.

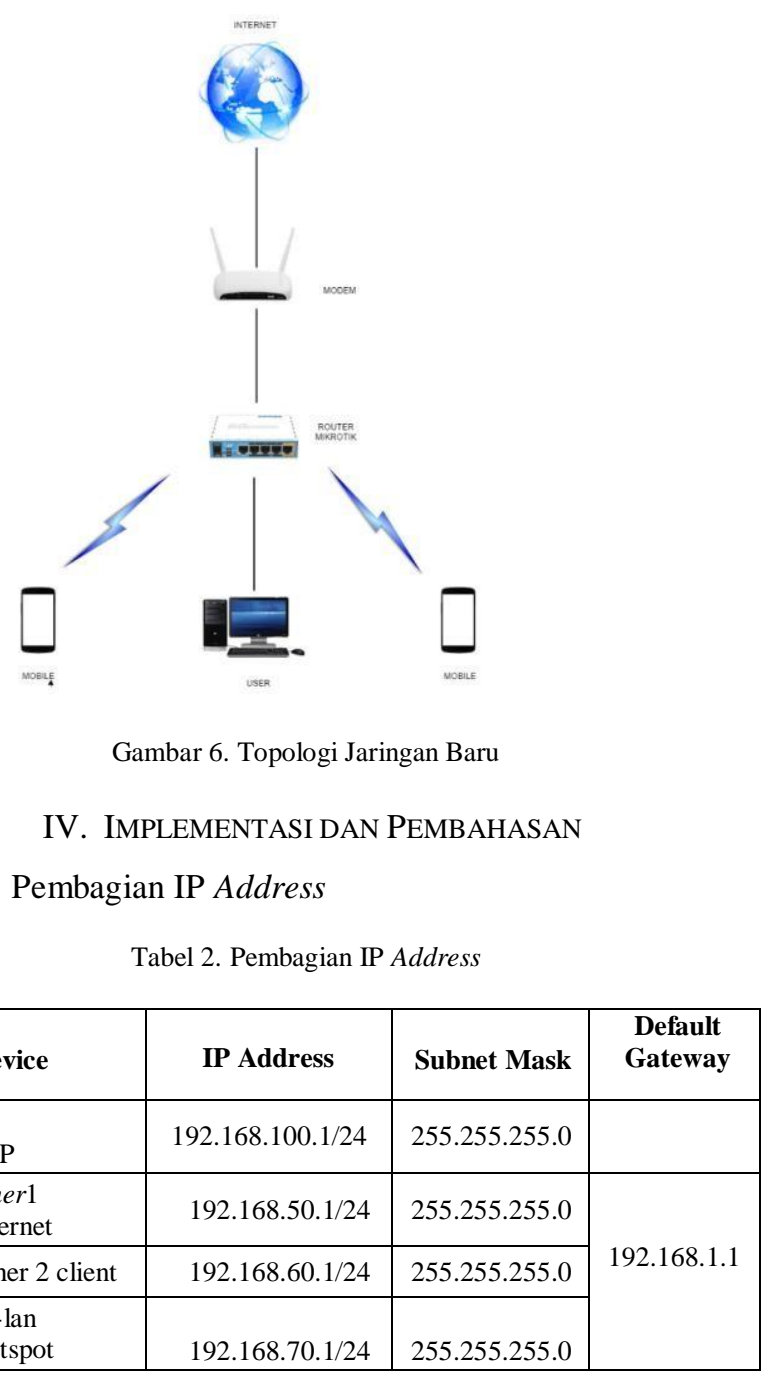

B. Rancangan Pembagian Alokasi Bandwidth

Tabel 3. Rancangan Alokasi Bandwidth

\begin{tabular}{|c|c|c|c|c|}
\hline \multirow{2}{*}{ Metode } & \multicolumn{2}{|c|}{ LAN } & \multicolumn{2}{c|}{ Hotspot } \\
\cline { 2 - 5 } & Upload & Download & Upload & Download \\
\hline $\begin{array}{c}\text { Queue } \\
\text { Simple }\end{array}$ & $5 \mathrm{Mb}$ & $1 \mathrm{Mb}$ & $7 \mathrm{Mb}$ & $1 \mathrm{Mb}$ \\
\hline $\begin{array}{c}\text { Queue } \\
\text { Tree }\end{array}$ & $5 \mathrm{Mb}$ & $1 \mathrm{Mb}$ & $7 \mathrm{Mb}$ & $1 \mathrm{Mb}$ \\
\hline
\end{tabular}

\section{Simlulation Prototyping}

Pada penelitian kali ini penulis melakukan simulasi menggunakan packet tracer, simulasi berupa mencoba merangkai dan melakukan konfigurasi berdasarkan perancangan yang sudah dilakukan, meliputi IP address, dan topologi. 
Jurnal Pseudocode, Volume VII Nomor 1, Februari 2020, ISSN 2355-5920, e-ISSN 2655-1845 www.ejournal.unib.ac.id/index.php/pseudocode

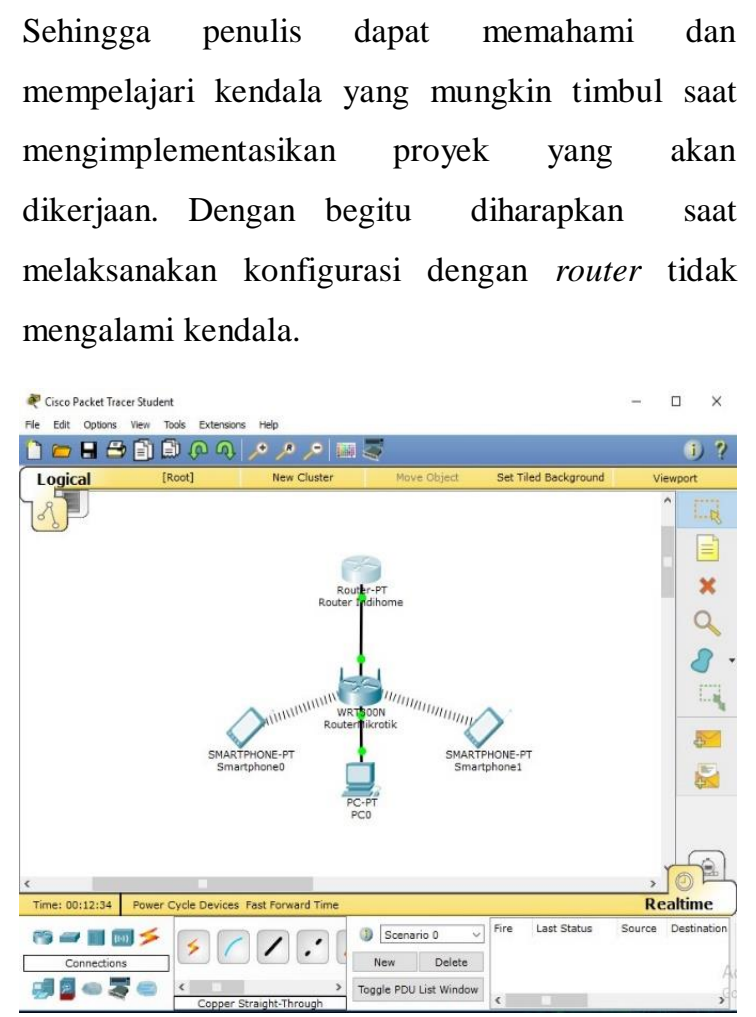

Gambar 7. Topologi Jaringan Baru

D. Implementation

Langkah atau tahapan dalam menggunakan

Mikrotik. Penggunaan pada Mikrotik berfungsi melakukan manajemen bandwidth.

\begin{tabular}{|c|c|c|c|c|}
\multicolumn{2}{c|}{ Tabel 4. Hasil Pengujian Bandwidth } \\
\hline \multirow{2}{*}{ Metode } & \multicolumn{2}{|c|}{$\mathrm{L}$} & \multicolumn{2}{c|}{ Hotspot } \\
\cline { 2 - 5 } & Upload & Download & Upload & Download \\
& & & & \\
\hline Queue & $\begin{array}{c}4.95 \\
\text { Simple }\end{array}$ & $0.90 \mathrm{Mb}$ & $\begin{array}{c}6.40 \\
\mathrm{Mb}\end{array}$ & $0.89 \mathrm{Mb}$ \\
\hline Queue & $\begin{array}{c}4.95 \\
\mathrm{Mb}\end{array}$ & $0.90 \mathrm{Mb}$ & $\begin{array}{c}6.78 \\
\mathrm{Mb}\end{array}$ & $0.98 \mathrm{Mb}$ \\
Tree & $\mathrm{Mb}$ & & \\
\hline
\end{tabular}

E. Management

Pada penelitian kali ini penulis memilih Simple Queue sebagai motede limitasi bandwidth yang dipakai. Dengan pertimbangan perbedaan yang tidak terlalu signifikan dengan metode Queue Tree dan konfigurasi yang cukup mudah bila suatu saat akan merubah limit bandwidth. Dengan demikian diharapkan peningkatan kualitas pelayanan karyawan pada pelanggan yang berbasis online bisa lebih optimal.

\section{KESIMPULAN}

Perbandingan manajemen bandwidth dengan metode Queue Simpel dan Queue Tree pada jaringan komputer dengan router mikrotik terdiri dari beberapa yaitu :

1. Pada penelitian ini penulis menggunakan metode Network Development Life Cycle (NDLC), sebuah metode yang bergantung pada proses pembangunan sebelumnya seperti perencanaan strategi bisnis, daur hidup pengembangan aplikasi, dan analisis pendistribusian data.

Tahapan metode ini meliputi analysis, design, simulation prototyping, implementation, monitoring dan management. Metode ini digunakan untuk merancang dan membandingkan metode Quеue Simpel dan Qиеие Tree pada jaringan komputer menggunakan Router Mikrotik.

2. Pada penelitian ini perancangan sistem baru dirasa cukup efektif untuk diterapkan pada jaringan skala kecil atau menengah,

3. Dengan menerapkan manajemen bandwidth Simple queue maupun Queue Tree kita dapat melakukan manajemen trafik dengan mengatur bandwidth upload download susuai yang kita mau, sehingga dapat mengatasi masalah trafik download upload yang tidak teratur.

\section{REFERENSI}

[1] Ariyus, Dony dan Rum Andri K.R. 2008.Komunikasi Data. Yogyakarta: Andi.

[2] Iqbal, Muhammad. 2017. Analisis Dan Perancangan

[3] Towidjojo, R. Mikrotik Kung Fu Kitab 2 Edisi 2016 Palu: Jasakom 